\title{
Peritoneal carcinomatosis of colorectal origin. Current treatment. Review and update
}

\author{
A. Gómez Portilla, I. Cendoya, I. López de Tejada, I. Olabarría, C. Martínez de Lecea, L. Magrach, \\ A. Gil, J. Echevarría, M. Valdovinos and I. Larrabide \\ Peritoneal Carcinomatosis Programme. Policlínica San José. Vitoria, Spain
}

\begin{abstract}
Colorectal cancer is the most frequent tumor of the digestive tract. The high incidence of abdominal dissemination; the poor prognosis of these patients, with median survival consistently ranging from 5 to 9 months in all studies of peritoneal carcinomatosis from colorectal cancer; the failure of adjuvant systemic chemotherapy treatment with a maximal survival of 18 months despite the development of new cytostatic drugs, and new combinations of use, make it crucial to search for and develop new treatment strategies.

We review the principles of Sugarbaker's treatment protocol, which involves the combination of maximum cytoreductive radical oncological surgery for the treatment of all macroscopically disseminated disease with maximum perioperative intraperitoneal intensification chemotherapy to treat residual microscopic disease.

We present the results of several scientific papers, all of them phase II studies with more than 10 patients treated, published in the medical literature by the main groups working in this line of treatment, together with the only phase III study reported and published so far, and finally the results of a recently reported retrospective international multicenter study. With this new alternative therapeutic approach, overall mean survival is $40 \%$ at 36 months, and $20 \%$ at 5 years.

Based on these results, this new therapeutic approach is proposed as the treatment of choice for these unfortunate patients.
\end{abstract}

Key words: Colorectal cancer. Sugarbaker's treatment protocol. Therapeutic approach.

Gómez Portilla A, Cendoya I, López de Tejada I, Olabarría I, Martínez de Lecea C, Magrach L, Gil A, Echevarría J, Valdovinos V, Larrabide I. Peritoneal carcinomatosis of colorectal origin. Current treatment. Review and update. Rev Esp Enferm Dig 2005; 97: 716-737.

Recibido: $12-01-05$

Aceptado: 18-01-05.

Correspondencia: A. Gómez Portilla. Director Programa Peritoneal Carcinomatosis. Policlínica San José. C/ Beato Tomás de Zumárraga, 10. 01008 Vitoria.e-mail: agomezpor@teleline.es

\section{INTRODUCTION}

Disseminated metastatic disease is the main cause of death in patients with colorectal cancer but, unlike other pathologies, the existence of disseminated disease of colorectal origin both in the abdominal cavity and remotely in the liver and lung does not rule out therapeutic approaches aimed at achieving a cure in selected groups of patients nowadays.

The high incidence of colorectal cancer, the most frequent digestive tumor; carcinomatosis affecting 10-20\% of patients either at the outset or during the course of the disease; the natural history of patients with peritoneal dissemination following colorectal cancer with survival rates below 6 months when treated using conventional therapeutic regimens; the failure of systemic chemotherapy in the treatment of these unfortunate patients in spite of the application of new drugs and chemotherapy, are all factors that made it essential to develop new attitudes and alternative therapies.

From 1982 onwards, Dr. Sugarbaker saw peritoneal seeding as a locoregional state of the disease and developed a new therapeutic alternative based on treating macroscopic disease with radical cytoreductive oncological surgery using the peritonectomies he developed, followed by treatment of residual microscopic disease by the direct intra-abdominal locoregional application of heated intraoperative intraperitoneal chemotherapy (HIIC) and early post-operative intra-abdominal chemotherapy (EPIC). With this new therapeutic regimen, his team is achieving survival rates above $30 \%$ at 5 years following completed cytoreductive operations, and in selected groups even the cure of patients who were hitherto mistakenly considered as end-stage (1).

These spectacular results led us to present an updated review of the principles behind this therapeutic alternative, which we have been using and developing in our setting as pioneers in Spain since 1997. At the same time, 
we would ask that this treatment alternative be taken into consideration by all professionals involved in the diagnosis and treatment of these unfortunate patients (2).

\section{NATURAL HISTORY OF UNTREATED CARCINOMATOSIS}

\section{Incidence of peritoneal carcinomatosis resulting from colorectal cancer}

Colorectal cancer is a public-health problem in Western countries, as it is the second most frequent neoplasm in men and the third most frequent in women. The worldwide incidence of colorectal cancer is estimated to be 945,000 patients per year (3). According to tumor registries in our country, 19,166 new cases of colorectal cancer were registered in Spain in 2000 (4). Many of these patients presented with metastasis and as many as $50 \%$ of them developed metastases during the course of the disease. The locations in which metastases are found in colorectal cancer are, in order of frequency, the liver, peritoneum, lungs, bones, and brain (5).

The precise incidence of peritoneal carcinomatosis as a site of recurrence is not clearly understood, as the majority of laboratory and imaging studies used in the follow-up of patients with colorectal cancer cannot detect the disease in its initial stages. It is estimated that, at the time of diagnosis, the peritoneal surface is already involved in $10-15 \%$ of cases, and that initial recurrence in the peritoneum occurs in up to $50 \%$ of patients after curative surgical excision of colon cancer. While it is well known that peritoneal dissemination appears in $40-70 \%$ of patients with recurrent disease, only $10-35 \%$ of patients have disease confined exclusively to the peritoneum (6-8). Treatment of disseminated abdominal disease still represents one of the limits of oncology (9).

The experience contributed by Wangesten's planned reinterventions since 1948 showed that recurrence was $64 \%$ at 6-12 months after initial surgery. Recurrence in almost $80 \%$ of cases was confined exclusively to the abdominal cavity (affecting the liver, and retroperitoneal lymphatic tissue with or without peritoneal involvement) (10).

In laparotomies performed on symptomatic patients, carcinomatous dissemination was present in half the patients, whereas it was the only site of recurrence in only $2-18 \%$ of cases. Brodsky's review (11) on the outcome of patients curatively treated for colorectal cancer showed that $25-35 \%$ of patients had peritoneal recurrence, and in $15 \%$ of these the peritoneum was the only site of metastatic disease. It is this small group of patients known as patients with predominant peritoneal dissemination (12) who may benefit from treatment with curative intent of their peritoneal carcinomatosis, provided that resection is complete.

\section{Natural history of carcinomatosis of colorectal origin}

The term peritoneal carcinomatosis was first used by Sampson in 1931 (13) to describe regional dissemination of cancer in patients with ovarian carcinoma. The dissemination mechanism was thought to be primarily implantation, although venous and lymphatic dissemination were considered in some cases. This concept has been generally accepted to this day.

Peritoneal carcinomatosis signifies the local intra-abdominal dissemination of gastrointestinal and gynecological cancers and other tumors with or without evidence of systemic metastatic disease. It is revealed by the presence of tumor nodules of varying size, number and distribution on the peritoneal surface. There are a great variety of individual manifestations of the disease, from the presence of a few small superficial nodules in the vicinity of the primary tumor to abdominal cavities completely filled with large invasive tumor deposits (14).

This regional involvement of cancerous disease has been traditionally associated with a poor prognosis and almost uniformly with incurability. The treatment of such patients has varied from laparotomies for taking biopsies to extensive resections of the tumor, with patients then being referred to their oncologists for treatment with systemic chemotherapy (15).

The majority of such patients suffered terribly, and in 9 months on average they died from intestinal obstruction or from starvation with end-stage cachexia. (16).

On occasion, patients needed a surgical intervention for intestinal occlusion, hemorrhage, or perforation, and sometimes for generalized ascites. However, because of the poor survival rates of these patients, some surgeons have argued in favor of abstentionist attitudes in selected cases $(17,18)$.

Peritoneal carcinomatosis is the commonest cause of death in patients who have had an intra-abdominal cancer resected (19). According to Sugarbaker (20), the persistence of tumor cells in the abdominal cavity or the pelvis is responsible for the death of $30-50 \%$ of patients dying from this disease.

Peritoneal metastases of colorectal cancer are currently considered the same as remote or disseminated metastatic disease, and is therefore treated with systemic chemotherapy or surgery together with systemic chemotherapy, both being only used for palliative outcomes (6).

There are few studies published on the natural history of carcinomatosis of colorectal origin. The median survival seen in patients suffering from colorectal carcinomatosis was 6 months for Chu et al. (14), 5.2 months in the multicenter study EVOCAPE by Sadeghi et al. (15), and 9 months in the largest and most recent series of Jayne et al. (21), as shown in table I.

Peritoneal carcinomatosis is thus a common form of disease progression in patients with colorectal cancer. Of 2,756 patients with colorectal cancer, 349 (13\%) were 
Table I. Survival in colorectal carcinomatosis

\begin{tabular}{lcccc}
\hline Author & Patients & Median & Mean & Maximum survival \\
\hline Chu (14) & 45 & $6 \mathrm{~m}$ & $8.5 \mathrm{~m}$ & $26 \mathrm{~m}$ \\
Sadeghi (15) & 118 & $5.2 \mathrm{~m}$ & & \\
Jayne (21) & 349 & $9 \mathrm{~m}$ & & \\
\hline
\end{tabular}

identified as having peritoneal carcinomatosis, 214 synchronously and 135 metachronously. Of the patients with synchronous disease, $125(58 \%)$ were free of metastatic disease, and 80 of them had localized peritoneal carcinomatosis, with carcinomatosis being defined as localized when only one of the 5 abdomino-pelvic regions was affected by the tumor. Mean survival in localized disease was 9 months, and 4 months when disease was generalized. In patients considered for operation, the extension of carcinomatosis seems to be the only indicator for survival (16).

The incidence of peritoneal carcinomatosis in this study was $13 \%$, comparable to that in other studies. The most relevant finding in the study is the group that developed localized carcinomatosis in the absence of disease at any other level, who are surely the patients who can benefit from cytoreductive surgery with intra-peritoneal perioperative chemotherapy (IPCH) (16).

Pestieau and Sugarbaker (1) have hypothesized that if colon carcinomatosis is of little volume and is treated using cytoreductive surgery with intraoperative intraperitoneal chemotherapy, survival rates at 5 years will improve. Complete cytoreduction is essential to achieve long-term survival. If all the visible cancer can be resected, residual disease can be eradicated by adequate intraperitoneal perioperative chemotherapy. Effective regional control will postpone death in the majority of cases, and will possibly cure some of the patients (22).

The natural history of this disease and the heterogeneity of patients are such that only a randomized prospective study would adequately answer the questions on whether locoregional treatment prolongs survival.

Although the benefits of cytoreductive surgery with intraoperative intraperitoneal chemotherapy should be validated by randomized prospective studies, there is interest in and growing enthusiasm for this new treatment option, particularly in the light of the terrible prognosis associated with conventional treatments (21).

Of patients with carcinomatosis of colorectal origin, $85 \%$ die with disease confined to the abdomen (23).

\section{ADJUVANTS WITH SYSTEMIC CHEMOTHERAPY IN ADVANCED CANCER OF THE COLON AND RECTUM}

For the last 40 years, 5-FU has been virtually the only chemotherapeutic agent effective in patients with advanced cancer of the colon and rectum, and is still con- sidered the main drug, although actually it only produces a complete response in $10 \%$ of patients, with a mean survival between 9 and 12 months, and only $5 \%$ of patients still alive 3 years later (24).

A meta-analysis of publications available in 1992 revealed a response rate of $11 \%$ for 5-FU as monotherapy, versus $23 \%$ when combined with folinic acid (25). Another comparative meta-analysis of the way of administering 5-FU showed the superiority of continuous infusion versus bolus in terms of response and survival $(26,27)$. The combinations of 5-FU/LV with oxaliplatin or irinotecan (CPT-11) are at present the most active treatments available for advanced colorectal cancer (2832).

Other chemotherapeutic agents are now being studied such as oral fluoropyrimidines (UTF, capecitabine), and raltitrexed (Tomudex), and they demonstrate equivalence in response rates with better tolerance when compared to classic regimens, with the advantage of oral administration in many cases. However, improvement in survival has not been achieved (33-35). The main multicenter randomized phase III studies of adjuvant chemotherapy are shown in table II.

Table II. Effectiveness of systemic chemotherapy in advanced colorectal cancer

\begin{tabular}{lccc}
\hline & Mean survival & 1 year & 2 years \\
\hline 5-FU monotherapy (24) & 10 months & & \\
de Gramont & 10 months & $37 \%$ & $12 \%$ \\
$\begin{array}{l}\text { (5-FU bolus + 2 days infusion } \\
\text { folinic acid) (30) }\end{array}$ & & \\
Lokich & 10 months & $40 \%$ & $16 \%$ \\
$\begin{array}{l}\text { (5-FU continuous + 2 days infusion } \\
\text { folinic acid) (36,37) }\end{array}$ & & \\
5- FU + folinic acid + oxaliplatin & $10-15$ months & \\
5-FU + folinic acid + irinotecan & $10-15$ months & \\
(38,39) & & \\
5-FU + oxaliplatin & 18 months & \\
5-FU + oxaliplatin + irinotecan (28) & 18 months & \\
Raltitrexed (40) & 10 months & $37 \%$ & $12 \%$ \\
\hline
\end{tabular}

The studies published on systemic therapy in advanced colorectal disease are not focused on disseminated peritoneal disease, but are mostly studies of hepatic involvement, as this is the easiest way of measuring the disease. Treatment for metastatic disease is not given with curative intent except in the case of hepatic or pulmonary metastases. It is only in patients with curative hepatic resections that survivals of $25-40 \%$ have been achieved at 5 years, although in $60-70 \%$ of cases the disease recurred in the liver or lung (41). The main objectives of medical treatment for advanced colorectal disease are thus to prolong survival and improve quality of life (42) in an at- 
tempt to make the disease chronic. The majority of cases with peritoneal metastases of gastrointestinal origin are relatively resistant to systemic cytostatic drugs, with a clear dose-dependent effect. Systemic chemotherapy is not enough, but neither is surgery alone (1).

In spite of the advances in chemotherapy drugs, there are no satisfactory treatments available for peritoneal carcinomatosis. The main reason for these pessimistic results may be that cytostatic drugs administered do not affect peritoneal metastases in a sufficiently high concentration (43).

\section{RADICAL ONCOLOGICAL CYTOREDUCTIVE SURGERY}

The main aim of any treatment with curative intent in oncological surgery is the complete eradication of malignant tumor tissue. This principle has been sufficiently demonstrated in the surgery of the primary tumor and in metastatic disease of the liver and lung (44).

The aim of cytoreductive surgery is to achieve a complete extirpation of macroscopic tumor disease (45). It was Sugarbaker who developed the specific surgical technique that made it possible to carry out the radical oncological cytoreductive surgery known as peritonectomy with the use of electrosurgery in patients with peritoneal carcinomatosis (46). As many as six different peritonectomies may be necessary to eradicate the disease, which may require between 8 and 12 hours of surgery (47). Peritonectomies are used exclusively in areas with visible tumor with the intention of leaving the patient with a disease reduced to a microscopic level. However, surgery alone cannot be complete at a microscopic level (1). The main drawback in the treatment of peritoneal disease is the impossibility of performing a complete surgical resection, as invisible dissemination is always present in the abdominal cavity (48). It is precisely the persistence of residual microscopic disease that the surgeon does not see that finally kills the patient (49).

Experience has shown that if only surgery is used, $100 \%$ of patients will relapse in spite of the fact that the disease is apparently localized and has been completely resected (50).

Reseeding of malignant cells in patients with peritoneal carcinomatosis on the surfaces of the peritonectomies must be expected unless there is an associated use of perioperative intraperitoneal chemotherapy. Respect for the peritoneum constitutes the first line of defense against carcinomatosis; peritonectomies are used exclusively in areas with visible tumor (20).

Failure to respect the peritoneum as the first line of defense against carcinomatosis results in:

1. Greater dissemination.

2. The development of implants in vital structures.

3. Deeper implants which cannot be extirpated through peritonectomies.

4. Less curative cytoreductions.
For these reasons peritonectomies are used exclusively in areas affected by the tumor, always respecting those free of tumor implantation.

In all cancers, early aggressive treatment of disseminated peritoneal disease at its minimal levels shows the best results (20). In peritoneal carcinomatosis of colorectal origin, it is only possible to achieve long-term survivals after having resected all the visible implants or affected organs (51).

However, on some occasions eradication of disease is not possible. The visceral peritoneum is the main limit, both in the hepatobiliary hilum and in the folds of the mesentery, and when there is massive involvement of the small intestine by tumor infiltration (52).

\section{THE INTEREST IN PERIOPERATIVE INTRAPERITONEAL CHEMOTHERAPY}

Interest in intraperitoneal chemotherapy is not new. In 1955, Weissberger collected the results of the treatment of 7 patients with ovarian cancer who had been treated with intraperitoneal chemotherapy using nitrogen mustard (53).

Pivotal pharmacokinetic studies were carried out by Dedrick in 1978 (54). In these it was found that hydrophilic cytostatic drugs could maintain a significant concentration gradient through the peritoneal-plasma barrier when they were instilled in the abdominal cavity in large volumes. However, they also showed in their studies that the greatest limiting factor for the clinical use of intraperitoneal chemotherapy was the scant penetration of the drugs in use within tumor tissue. At present, it is believed that the diffusion of cytostatics is at a maximum between 1-3 $\mathrm{mm}$ in the periphery of the tumor (55).

For these reasons, it is generally accepted today that only patients with minimal residual disease after surgery are candidates who may benefit from intraperitoneal chemotherapy. A complete extirpation of macroscopic tumor disease is often not possible. A majority of groups consider that intraperitoneal chemotherapy is only useful if residual tumor nodules are smaller than $3 \mathrm{~mm}$ in size.

The administration de intraperitoneal chemotherapy has the benefit of providing higher concentrations of cytostatics locally at the tumor site, while minimizing systemic toxic effects when compared to systemic intravenous administration (56).

Intraperitoneal chemotherapy in the treatment and prevention of peritoneal disease was introduced at the beginning of the 1980's (20). In 1985, Sugarbaker was already advising that intraperitoneal chemotherapy was to be used for advanced colorectal cancers (57).

Gilly (58) contributed the first European experience, following the school of Fujimoto and Koga $(59,60)$.

Basically, the Western group under the leadership of Sugarbaker specializes particularly in colorectal carcinomatosis and peritoneal pseudomyxoma, while Eastern re- 
searchers led by Yonemura focus on gastric carcinomatosis.

There are three reasons why the use of intraperitoneal chemotherapy has had a limited success and little acceptance among oncologists:

- The limited penetration of drugs in tumor nodules. Only the most external cell layers are penetrated by cytostatics, which makes it essential to concentrate on the residual microscopic disease in the protocols for this type of treatment.

- The lack of uniform distribution of cytostatics in the abdominal cavity because of adherences and the presence of a large mass of tumor.

- The unsuitable choice of patients.

Nowadays there have been important changes in the use of chemotherapy. Firstly in the route of administration: chemotherapy is now administered intraperitoneally, and acts where the disease is. There has also been a change in timing, as chemotherapy begins to be administered intra-operatively in the operating room itself as soon as the cytoreductive extirpation of macroscopic disease has finished, when only residual microscopic disease is left. Finally, a third change has come about in the selection criteria for the patients who are candidates for this treatment: as it is necessary to carry out a complete cytoreduction of the disease before administering cytostatics, the size of the residual implant is of crucial importance $(20,47,61)$.

The major change has yet to be made, and that will be a change in the attitude of oncologists towards the treatment of advanced colorectal disease, as peritoneal carcinomatosis is potentially curable with the early application of this new combined treatment (20).

\section{BENEFITS OF INTRAPERITONEAL HYPERTHERMIC CHEMOTHERAPY}

The therapeutic use of heat has been known since the aphorism by Hypocrates (section VII, \# 83), who said that what medicine does not cure, iron cures (the scalpel); what iron does not cure, fire cures, and what fire does not cure is really incurable (62).

Heat in itself has a cytotoxic effect due to its action on DNA repair, protein denaturalization, induction of thermal shock proteins, induction of apoptosis, and inhibition of angiogenesis.

True hyperthermia is defined as a temperature of $41{ }^{\circ} \mathrm{C}$ or more. The synergism of cytostatics can also occur at temperatures between 39 and $41{ }^{\circ} \mathrm{C}$.

There is still no consensus about the optimum temperature during hyperthermic chemotherapy. As was said before, synergism begins at temperatures of $39^{\circ} \mathrm{C}$, but is greater at higher temperatures. On the other hand, temperatures above $43{ }^{\circ} \mathrm{C}$ do not represent a greater synergism and do entail the development of lesions of the small intestine due directly to the thermal effect (63).
Spratt began experimental studies to find a local treatment for carcinomatosis that would combine chemotherapy with hyperthermia. These studies finally resulted in the first application of intraoperative intraperitoneal chemohyperthermia in the treatment of peritoneal pseudomyxoma in humans in February 1979 (64,65).

The thermic exchangers used in current practice were designed for use in extracorporeal circulation and therefore have a temperature limit of $41{ }^{\circ} \mathrm{C}$ to avoid the lysis of red blood cells. For this reason, and due to the loss of temperature of the circuits employed for the administration of chemotherapy, it is not possible to attain more than moderate hyperthermia with the conventional instruments on the market. We have managed to incorporate a supplementary heater in the circuitry, which ensures a uniform temperature of $42^{\circ} \mathrm{C}$ in the cavity throughout the procedure.

The open technique of chemohyperthermia allows continuous control of the irrigating solution, avoiding the damage local heat may induce in the intestine by prolonged contact on the same spot: at the same time it ensures a homogenous distribution throughout the cavity without leaving nooks and crannies hidden from exposure. Studies by the Washington Cancer Institute permit the affirmation to be made that no risk is involved for the theatre staff during the practice of this technique (66).

\section{CHOICE OF DRUGS AND PHARMACOKINETICS}

The pharmacokinetic advantages of intraperitoneal chemotherapy are the most important factor in the rational use of IPCH for the malignant disease of the peritoneal surface.

The movement of high-molecular-weight drugs from the peritoneal cavity to the circulatory compartment of the body is much slower than the clearing of the drugs from the systemic compartment. This principle creates a concentration gradient due to the peritoneum-plasma barrier that is strongly in favor of intraperitoneal concentration. Substances with a high molecular weight are confined in the abdominal cavity for long periods of time and facilitate intensification therapies. The performance of peritonectomies with extirpation of the parietal peritoneum does not alter the "peritoneal cavity sanctuary" phenomenon (20).

- The cytostatic drugs used should have the following characteristics:

- They should have a high molecular weight and be hydrosoluble.

- They should clear rapidly from the systemic circulation, and their effectiveness should be synergetic with hyperthermia.

- They should not be cell cycle-specific, being cytotoxic even in relatively short periods of exposure.

The drugs most commonly used and studied as intraperitoneal chemotherapeutic agents have been intra- 
operative MMC (mitomycin C) with a peritoneum-plasma concentration gradient greater than $28(67,68)$, together with 5-fluorouracil as an early postoperative intraperitoneal chemotherapy regimen (69). Recently the intraperitoneal application of new drugs considered as second-line in the systemic treatment of advanced disease is being studied (70,71). The best results have been achieved using these new strategies with survivals at 2 years of $74 \%$, and it is suggested that the addition of irinotecan to the oxaliplatin might even in the future improve the effectiveness of this intra-abdominal locoregional intensification treatment (72).

It seems that the higher the abdominal temperature, the greater is the peritoneum-plasma concentration gradient. The duration of perfusion does not seem to bear any relation to the peritoneum-plasma gradient. In the majority of studies the mean life of the drug is 90 minutes or less. There are not enough studies on the depth of penetration of MMC after intraperitoneal administration, but there are studies on its penetration following administration by vesical instillation, thus demonstrating its presence in the urothelium, lamina propria and even muscle layers, which suggests that it penetrates at least a few millimeters (73).

Little work has been published on the maximum tolerated dose in HIPEC. Pharmacokinetic studies carried out by the Cancer Institute of Holland have demonstrated an unacceptable systemic toxicity at doses of $40 \mathrm{mg} / \mathrm{m}^{2}$, and they established a limit in their treatment standard of 35 $\mathrm{mg} / \mathrm{m}^{2}$ (6). Table III shows the primary drugs suitable for use in HIPEC.

Table III. Area under the curve for drugs clinically used in the treatment of disseminated peritoneal disease

\begin{tabular}{lcc}
\hline Drug & Molecular weight & Peritoneum-plasma gradient \\
\hline 5- Fluorouracil & 130 & $250-1400$ \\
Mitomycin C & 334 & $75-80$ \\
Doxirubicin & 544 & 500 \\
Cisplatin & 300 & $12-20$ \\
Taxol & 808 & 1000 \\
Gemcitabine & 263 & 50 \\
\hline
\end{tabular}

\section{SELECTION OF PATIENTS. PERITONEAL CARCINOMATOSIS INDEXES}

The introduction of cytoreductive surgery combined with regimens of intraperitoneal chemotherapy promises increased survival time for selected patients with peritoneal carcinomatosis (1).

This aggressive treatment option for disseminated peritoneal disease includes peritonectomies for the treatment of macroscopic disease, administration of HIPEC for the control of microscopic disease, and a prudent selection of patients.
The clinical variables necessary for the selection of suitable patients include: histological type of tumor (invasive progression compared to expansive or by apposition), degree of existing disease, and extent of cytoreduction achieved. A correct selection of patients is mandatory in order to optimize results (46).

Different indexes have been used for the degree of peritoneal involvement, which enable patient stage to be ascertained and correlated with results obtained (74).

Gomez Portilla and Sugarbaker (75-77) have developed an objective method to establish the degree of existing disease that is known as the Peritoneal Carcinomatosis Index (PCI). With this method, the presence of disease and its size are measured in 13 different abdominal regions before carrying out cytoreductive surgery. On completing cytoreduction, the degree of residual disease is determined using the Index of Cytoreduction achieved, which reflects the absence of residual macroscopic disease.

Both Indexes, the Peritoneal Carcinomatosis Index and the Index of Cytoreduction achieved are the main prognostic factors in this type of conditions (20).

Using these indexes is essential, as it will help in the selection of patients and will avoid unnecessary surgery in high risk patients who just will not benefit form this treatment modality, given that it has only been possible to reach prolonged survivals in patients in whom a complete cytoreduction has been achieved (20). Surgeons should bear in mind that no long-term survivors exist unless a complete cytoreduction has been carried out. The presence of residual disease in difficult and crucial anatomical sites may on occasion jeopardize an initially favorable peritoneal carcinomatosis index (46). Patients with systemic metastatic disease are obviously not candidates for this treatment (6). Table IV shows the clinical factors that determine the surgical approach to carcinomatosis.

Table IV. Surgical approach to the treatment of carcinomatosis

\begin{tabular}{lcc}
\hline & $\begin{array}{c}\text { Oncological } \\
\text { cytoreduction }\end{array}$ & $\begin{array}{c}\text { Conventional } \\
\text { treatment }\end{array}$ \\
\hline Surgical risk of patient & Low & High \\
Histological grade & Low & High \\
Interval between operations & Long & Short \\
Type of ascites & Mucinous & Serous \\
Hepatic / remote metastases & Absent & Present \\
Complete cytoreduction & Possible & Impossible \\
Reestablishment of intestinal function & Possible & Impossible \\
\hline
\end{tabular}

The use of PCI will in the future enable the selection of patients suitable for oncosurgical treatment, with indices of peritoneal carcinomatosis greater than 24 representing a contraindication (77). 


\section{TECHNIQUE-ASSOCIATED MORBIDITY AND MORTALITY}

The morbidity and mortality associated with this combined therapy of radical oncological cytoreduction and abdominal intensification chemotherapy are high (1).

Complications may derive directly from surgery, hyperthermia or chemotherapy, or from a combination of all these factors.

There is great variation regarding the reported morbidity and mortality: morbidity rates of $0-43 \%$ and mortality rates of $0-20 \%(6,52,74,78-80)$. The principal causes of death are intestinal perforation or suture dehiscence. The formation of intestinal fistulas has also been described, as well as leakage of bile, pancreatitis, and postoperative hemorrhage. Among systemic complications, apart from those usual in complex surgery (deep vein thrombosis, pulmonary emboli, pneumothorax, cardiac insufficiency or cerebral infarcts), bone marrow aplasia or the development of toxic hematological effects are the most feared complications.

It is difficult to separate the secondary complications of surgery from those related to HIPEC, both because of the heat and because of cytostatics, but the majority of complications described appear mainly in relation to the degree of surgical aggression. The most frequent intestinal complication is still intestinal perforation caused by surgical trauma of the intestinal surface during resection of the visceral implants, possibly aggravated by the action of heat and cytostatic drugs (6). However, Shido et al. have demonstrated that hyperthermia is of itself not responsible for visceral damage when used in procedures with HIPEC (64).

The contribution of postoperative diagnostic studies with imaging techniques (81) to differentiate minor complications due to inflammatory response from major complications requiring treatment, fistulas, abscesses, and hemoperitoneum will allow a greater understanding of and a solution for these difficult patients in the future.

Bone marrow aplasia is clearly the result of the application of intraperitoneal chemotherapy, and is dose- and drug-dependent. The nadir of bone marrow aplasia develops two weeks after intraperitoneal chemotherapy, compared to 4-6 weeks in systemic chemotherapy (82).

Toxic renal insufficiency appears when using regimens with cisplatin, and hence the use of thiosulphate chelating agents is always required.

Mortality and morbidity are in direct relation to the learning curve and the surgical technique employed, as well as the magnitude of the cytoreduction performed. Surgeons should always carefully discuss the balanced postoperative risk such extensive surgery entails against benefits in terms of survival and quality of life.

Studies carried out on the quality of life of these patients indicate that the survivors tolerate the treatment reasonably well, and that after 3 months they return to their usual life pattern. A recent study on patients with survivals longer than 3 years after cytoreduction and intraperitoneal chemotherapy have demonstrated that $47 \%$ of them had been able to return to work, and $82 \%$ claimed to have attained $90-100 \%$ of their normal activity, and none of the patients regretted the treatment received. Without doubt this endeavour provides hope and optimism in a patient group that until now had limited therapeutic options, and whose survival without this intensive treatment, in spite of the accompanying morbidity, would be impossible (83).

\section{STUDIES PUBLISHED IN THE MEDICAL LITERATURE}

\section{Phase II studies}

Phase II studies of the treatment of carcinomatosis due to colorectal and pseudomyxoma are very numerous and promising (1,6,77-106).

In table $\mathrm{V}$ we present all series published, excluding the Sugarbaker group, with more than 10 patients with carcinomatosis of colorectal origin treated with cytoreduction and perioperative intraperitoneal chemotherapy.

Table V. Colorectal carcinomatosis treated with cytoreduction + intraperitoneal chemotherapy

\begin{tabular}{|c|c|c|c|c|c|c|c|c|}
\hline \multirow{3}{*}{ Author } & \multicolumn{8}{|c|}{ Series published } \\
\hline & \multirow[t]{2}{*}{ Year } & \multirow[t]{2}{*}{ Patients } & \multirow{2}{*}{$\begin{array}{l}\text { Average } \\
\text { follow-up }\end{array}$} & \multicolumn{5}{|c|}{ Survival in years } \\
\hline & & & & 1 & 2 & 3 & 4 & 5 \\
\hline Schneebaum & 1996 & 15 & 15 months & & & & & \\
\hline Elias & 1997 & 23 & 12 months & $88 \%$ & $55 \%$ & $40 \%$ & & \\
\hline Fujimura & 1999 & 14 & & $51 \%$ & & $21 \%$ & & \\
\hline Loggie & 2000 & 38 & 27 months & $60 \%$ & $39 \%$ & $24 \%$ & & \\
\hline Cavaliere & 2000 & 14 & 30 months & & $64 \%$ & & & \\
\hline Witkamp & 2000 & 29 & 38 months & $82 \%$ & $45 \%$ & $23 \%$ & & \\
\hline Beaujard & 2000 & 21 & 12 months & $50 \%$ & & & & \\
\hline Piso & 2001 & 17 & 39 months & & & & $75 \%$ & \\
\hline Elias & 2001 & 64 & 36 months & $60 \%$ & $47 \%$ & $36 \%$ & & $27 \%$ \\
\hline Culliford & 2001 & 47 & 17 months & & & & & $28 \%$ \\
\hline Zoetmulder & 2002 & 35 & & & & & & $20 \%$ \\
\hline Shen & 2003 & 40 & 52 months & $60 \%$ & & $24 \%$ & & \\
\hline Pilati & 2003 & 34 & 14 months & & $31 \%$ & & & \\
\hline Glehen & 2003 & 26 & & & & & & \\
\hline Total* & & 306 & 10-52 months & & $>40 \%$ & & & $20 \%$ \\
\hline & & & & & 2 years & & & 5 years \\
\hline
\end{tabular}

* Patients in the various publications by a same group have been counted only once, and patients with carcinomatosis of appendicular origin have been excluded from among their cases.

This literature review clearly suggests that at least some benefit can be achieved, and on occasion a cure in patients who were formerly considered only for palliative treatment. The joint application of cytoreductive surgery with intraperitoneal chemotherapy is a procedure that is feasible and safe. The determining prognostic factor in all these series has been the degree of cytoreduction 
achieved, given that the synergy of chemotherapy and hyperthermia depends directly on the amount of residual disease.

Carcinomatosis and hence peritoneal involvement should be considered as affecting one organ, just as the liver or lung; they should be treated the way such organs are, with curative intent. Peritoneal carcinomatosis resulting from most gastrointestinal cancers with a low index of peritoneal carcinomatosis, where good indices of complete cytoreduction can be attained, should be routinely treated according to the protocols of the new combined alternative treatment of radical oncological cytoreduction and perioperative intraperitoneal intensification chemotherapy. The natural history of these patients is changing with the occurrence of metastases in more distant sites such as the brain or eye.

In Sugarbaker's personal experience, $50 \%$ of patients with peritoneal carcinomatosis can achieve lengthy survival with the use of peritonectomies, intraperitoneal chemotherapy, and a proper selection of patients (20). In carcinomatoses of colorectal origin in his series, with more than 100 treated patients, he reports $40 \%$ survival at 5 years; the main prognostic factor was Peritoneal Carcinomatosis Index, which conditioned the degree of cytoreduction obtained $(1,47,89,105,106)$.

\begin{tabular}{cc}
\hline Peritoneal Carcinomatosis Index & Survival at 5 years \\
$<10$ & $50 \%$ \\
$11-20$ & $20 \%$ \\
$>20$ & $0 \%$ \\
\hline
\end{tabular}

Although it is true that these studies have all been retrospective and non-randomized, and are therefore susceptible of criticism, everything indicates that, with this new therapeutic alternative, better survivals and on occasion cures unthinkable thus far are being obtained.

\section{Phase III study}

Until now the main objection put forward to this therapeutic alternative was a lack of randomized prospective studies, but in spite of proposals for ethically and scientifically correct studies, patients refused to be included or not in the treatment by chance. Studies had to be abandoned on several occasions, as happened in all those proposed at the Gustave Roussy Institute in Paris (72).

Recently Zoetmulder has presented the results of a phase III study carried out in patients with carcinomatosis of colorectal origin by examining the application of intraperitoneal chemotherapy versus systemic chemotherapy (107-109), which have already been officially published (110).

In this study, 105 patients were recruited. The aim was to compare a control group receiving conventional treatment with 5-FU/leucovorin (given systemically) to the study group, in which as well as cytoreductive surgery, intraoperative intraperitoneal treatment with MMC modulated by hyperthermia was applied followed by systemic chemotherapy with 5-FU/leucovorin as shown in table VI.

Table VI. Phase III study: systemic chemotherapy versus intraperitoneal chemotherapy + systemic chemotherapy

\begin{tabular}{ll}
\hline Control Group & HIPEC Group \\
\hline Palliative or minimal surgery & Oncological cytoreduction + HIPEC (MMC) \\
Weekly 5-FU/leucovorin & Weekly 5-FU/leucovorin \\
During 6 months or progression & During 6 months or progression \\
Any second line therapy & Any second line therapy \\
\hline
\end{tabular}

The general characteristics of patients in both groups were similar, as shown in table VII.

Table VII. General characteristics of the study groups. Phase III study: systemic chemotherapy versus intraperitoneal chemotherapy + systemic chemotherapy

\begin{tabular}{lcc}
\hline & Control Group & HIPEC Group \\
\hline Patients & 51 & 54 \\
Men/women & $24 / 27$ & $34 / 20$ \\
Mean age & 55 & 53 \\
Primary/secondary & $28 / 23$ & $30 / 24$ \\
Appendix & 11 & 7 \\
Colon & 34 & 41 \\
Rectum & 6 & 6 \\
\hline
\end{tabular}

In the study group the degree of oncological cytoreduction obtained was complete (R1), without residual macroscopic disease, in 18 patients (38\%). The residual disease was $<2.5 \mathrm{~mm}$ (R2a) in 21 of the patients $(43 \%)$, and adequate cytoreduction was not obtained, leaving macroscopic disease $>2.5 \mathrm{~mm}$ in 9 patients $(19 \%)$.

The degree of cytoreduction obtained was the main prognostic factor in this study, and in spite of achieving a complete cytoreduction in only less than $40 \%$ of patients, the survival rate was greater than with any other treatment known to this date, as is reflected in table VIII.

Table VIII. Survival. Phase III study: systemic chemotherapy versus intraperitoneal chemotherapy + systemic chemotherapy

\begin{tabular}{lcc}
\hline & Control group & HIPEC Group \\
\hline & 50 & 53 \\
6 months & 39 & 37 \\
12 months & 18 & $26(43 \%)$ \\
18 months & 8 & 20 \\
24 months & 5 & $11(20 \%)$ \\
30 months & 2 & 7 \\
36 months & 0 & $4(7.5 \%)$ \\
\hline
\end{tabular}


The median survival of both groups was more than one year, with median survival in the cytoreduction + intraperitoneal chemotherapy group having been almost twice that achieved in the treatment group receiving systemic chemotherapy (22.4 versus 12.6 months); furthermore, at 2 years $20 \%$ of patients treated with intraperitoneal chemotherapy were alive.

These partial results, in spite of having been obtained with very poor cytoreductions (only $40 \%$ of patients received a $\mathrm{CC} 0-\mathrm{CC} 1$ cytoreduction), and applying intraperitoneal chemotherapy exclusively intra-operatively for 60 minutes with MMC, have shown such great benefits in this group of patients that it was imperative to close the study, as it was not ethically correct to continue with treatments other than this new combined intraperitoneal therapeutic alternative.

\section{Multicenter international study}

In January 2004, Glehen et al. $(7,8)$ presented the results of their international multicenter retrospective study in which they collected the experience worldwide of this new alternative treatment for patients suffering from colorectal carcinomatosis, excluding carcinomatosis originating in the appendix.

The study focused on 506 patients from 28 institutions who had been treated with cytoreductive surgery and perioperative intraperitoneal chemotherapy, with a mean follow-up of 53 months. Mean survival was 19.2 months, with survival at one year of $72 \%$, at three years of $39 \%$, and at five years of $19 \%$. There were 38 patients who had exceeded 5 years' survival after cytoreduction in spite of having had diffuse peritoneal carcinomatosis.

Again, the degree of cytoreduction achieved was the primary determinant of prognosis, with survivals of $31 \%$ at 5 years when a complete macroscopic eradication of disease was attained, as shown in table IX.

Table IX. Survival according to degree of cytoreduction. International Multicenter Study (8)

\begin{tabular}{lccccc}
\hline $\begin{array}{l}\text { Degree of } \\
\text { cytoreduction }\end{array}$ & Patients (\%) & \multicolumn{2}{c}{$\begin{array}{c}\text { Survival } \\
\text { 3 years }\end{array}$} & 5 years & Mean follow-up \\
\hline CCR-0 & $271(53.5 \%)$ & $87 \%$ & $47 \%$ & $31 \%$ & 32.4 months \\
CCR-1 & $106(20.9 \%)$ & $79 \%$ & $29 \%$ & $15 \%$ & 24 months \\
CCR-2 & $129(25.4 \%)$ & $38 \%$ & $6 \%$ & $0 \%$ & 8.4 months \\
Overall & 506 & $72 \%$ & $39 \%$ & $19 \%$ & 53 months \\
\hline
\end{tabular}

\section{FUTURE LIMITS OF SURGERY FOR ADVANCED CANCER OF THE COLON AND RECTUM}

Without doubt there are reasons for continuing with treatment of peritoneal carcinomatosis of colorectal origin. An increasing number of institutions and hospitals are adopting this treatment strategy for preventing and treating malignant diseases of the peritoneal surface.
When should clinical research become standard practice? The majority of surgeons would be in favor of phase III trials to answer questions raised by the treatment of carcinomatosis of colorectal origin, but traditionally surgery has not advanced in the treatment of gastrointestinal tumors with randomized studies, but rather has developed through an evolutionary process. As an example, we offer the case of the surgical treatment of liver metastases, which in the absence of phase III studies has been validated by many groups and evolved over the years. After many discussions, it has come to be considered a new standard of medical practice (1).

For 30 years the treatment of liver metastases advocated by Makuuchi has been considered palliative, but nowadays nobody doubts that the radical surgical oncological treatment of metastases is the standard treatment against which any other therapeutic alternative must be judged. In the same way, surgery of pulmonary metastases is accepted, and on occasion so is surgery of cerebral metastases, as a procedure with curative intent.

We trust that the review of both the studies published in both the phase II, and phase III studies of Zoetmulder et al., or the international multicenter data collected in the study of Glehen et al., will permit that surgical treatment of peritoneal dissemination in colorectal cancer be also admitted as standard treatment for these patients. The latter offers without doubt the best survival results, and even some patients remain disease-free after more than 5 years, thus being potentially cured. In our opinion, as Sugarbaker states, we are at a point of no return given that this treatment strategy is effective, and its validation as standard clinical practice will come about as more phase II studies are published by more centers and institutions. It is impossible to carry out a phase III trial because of the patients' refusal to take part in a control group, and ethical issues arise when using any treatment other than this new therapeutic option, as it is the one that has resulted in the best outcomes so far.

The presence of liver metastases has until now represented a limitation to the treatment of patients with peritoneal dissemination, as it is considered a systemic disease disseminated through the hematogenous portal route. However, Elias (61) has demonstrated that on occasion a simultaneous approach to peritoneal disease in the course of surgery for hepatic metastasis has been tolerated by patients and proven effective when complete cytoreduction is attained. Initially 12 of their patients were treated using hepatectomy together with complete cytoreduction of the accompanying peritoneal disease, and early postoperative intraperitoneal chemotherapy. There was no mortality in their series, and no systemic complications from chemotherapy either; after a mean follow-up of 14.4 months no recurrence of peritoneal disease was found in any of the patients, and 7 of them are free of disease. The combination of hepatectomy and cytoreductive surgery in advanced colorectal cancer seems at present to be a logical and feasible treatment that is 
achieving promising survival results. More recently, this group has published the results of 37 patients treated simultaneously for recurrent hepatic and peritoneal disease with this combination therapy. There was a survival rate of $28 \%$ at 3 years and of $16 \%$ at 5 years, results that were absolutely unthinkable until now (111).

Today we may suggest that the current limits to the treatment of colorectal disease are found when said disease is restricted to the abdominal cavity (locoregional recurrence, retroperitoneal lymphatic dissemination, peritoneal dissemination or liver metastases), surgery ensures a radical oncological resection of disease, and this is always accompanied by the treatment of residual microscopic disease through the simultaneous administration of perioperative intraperitoneal chemotherapy.

In view of such outstanding results it is to be hoped that scepticism in the oncological community will in the future allow that all patients suffering from carcinomatosis of colorectal origin be referred to centers with experience in this therapeutic intraperitoneal combination alternative, thus enabling a chronification of their disease and in some cases their cure. Similarly, it would be desirable that Healthcare Authorities, both on a national and autonomic basis, facilitated and promoted a specific program for this treatment, commissioning National Reference Groups or Centers with proven experience to oversee it and develop it.

\section{REFERENCES}

1. Pestieau SR, Sugarbaker PH. Treatment of primary colon cancer with peritoneal carcinomatosis. Comparison of concomitant vs. delayed management. Dis Colon Rectum 2000; 43 (10): 1341-8.

2. Gómez Portilla A. Tratamiento quirúrgico de la carcinomatosis peritoneal de origen colorrectal. Cir Esp 2004; 75 (3): 156.

3. Bottomley A. Metastatic colorectal cancer: treatment challenges and quality of life. Lancet 2002; 359 (4): 1537-8.

4. Ortiz Hurtado H. Tratamiento quirúrgico y resultados del cáncer de colon. Presentación. Cir Esp 2003; 73: (1): 1.

5. Kindler HL, Shulman Kl. Metastatic colorectal cancer. Current Treatment Options in Oncology 2001; 2: 459-71.

6. De Bree E, Witkamp A, Zoetmulder FAN. Intraperitoneal chemotherapy for colorectal cancer. Review article. J Surg Oncol 2002; 79: 4661.

7. Glehen O, Kwiatkoski M, Sugarbaker PH, Elis D, Levine EA, Gilly $\mathrm{FN}$, et al. Cytoreductive surgery combined with perioperative intraperitoneal chemotherapy for the management of peritoneal carcinomatosis from colorectal cancer. A multi-institutional study of 506 patients. ASCO, 2004; January: 22-4.

8. Glehen O, Kwiatkoski M, Sugarbaker PH, Elias D, Levine EA, Gilly $\mathrm{FN}$, et al. Cytoreductive surgery combined with perioperative intraperitoneal chemotherapy for the management of peritoneal carcinomatosis from colorectal cancer. A multi-institutional study of 506 patients. J Clin Oncol 2004; 22 (3): 284-329.

9. Sticca RP. Peritoneal carcinomatosis: a final frontier. Ann Surg Oncol 2003; 10 (5): 484-5.

10. Gunderson LL, Sosin H, Levitt S. Extrapelvic colon areas of failure in a reoperation series: implications for adjuvant therapy. Int J Radiat Oncol Biol Phys 1985; 11: 731-41.

11. Brodsky JT, Cohen AM. Peritoneal seeding following curative resection of colonic carcinoma: implication for adjuvant therapy. Dis Col Rectum 1991; 34: 723-7.

12. Alonso O, Sugarbaker PH. Adult respiratory distress syndrome occur- ring in two patients undergoing cytoreductive surgery plus perioperative intraperitoneal chemotherapy. Case reports and a review of the literature. Am Surg 2000; 66: 1032-6.

13. Sampson JA. Implantation peritoneal carcinomatosis of ovarian origin. Am J Pathol 1931; 7: 423-43.

14. Chu DZJ, Lang NP, Thompson C, Osteen PK, Westbrook KC. Peritoneal carcinomatosis in non-gynecological malignancy: a prospective study of prognostic factors. Cancer 1989; 63: 364-7.

15. Sadeghi B, Arvieux C, Glehen O, Beaujard AC, Rivpoire M, Baulieux $\mathrm{J}$, et al. Peritoneal carcinomatosis from non-gynecological malignancies: results of the EVOCAPE 1 multicentric prospective study. Cancer 2000; 88: 358-63.

16. Esquivel J, Angulo F, Bland RK, Stephens AD, Sugarbaker PA. Hemodynamic and cardiac function parameters during heated intraoperative intraperitoneal chemotherapy using the open "coliseum technique". Ann Surg Oncol 2000; 7 (4): 296-300.

17. Scoggins CR, Meszoley IM, Blanke CD, Beauchamp RD, Leach SD Nonoperative management of primary colorectal cancer in patients wit stage IV disease. Ann Surg Oncol 1999; 6 (7): 651-7.

18. Blair SL, Chu DZJ, Schwartz RE. Outcome of palliative operations for malignant bowel obstruction in patients with peritoneal carcinomatosis from non-gynecological cancer. Ann Surg Oncol 2001; 8 (8): 632-7.

19. Pilati P, Rossi CR, Mocellin S, Foletto M, Scagnet B, Pasetto L, et al. Multimodal treatment of peritoneal carcinomatosis and sarcomatosis. Eur J Surg Oncol 2001; 27: 125-34.

20. Sugarbaker PH. Successful management of microscopic residual disease in large bowel cancer. Cancer Chemother Pharmacol 1999; 43 (Supl.): S15-S25.

21. Jayne DG, Fook S, Loi C, Seow-Choen F. Pritoneal carcinomatosis from colorectal cancer. Br J Surg 2002; 89: 1545-50.

22. Witkamp AJ, De Bree E, Van Goethem AR, Zoetmulder FAN. Antitumor treatment. Rationale and techniques of intra-operative hyperthermic intraperitoneal chemotherapy. Cancer Treatment Reviws 2001; 27: 365-174.

23. Willet CG, Tepper JE, Cohen AM, Orlow E, Welch CE. Failure patterns following curative resection of colonic carcinoma. Surgery 1984; 200 (6): 685-90.

24. Massacesi C, Pistilli B, Valeri M, Lippe P, Rocchi MBL, Cellerino R, et al. Predictors of short- term survival and progression to chemotherapy in patients with advanced colorectal cancer treated with 5-fluorouracil based regimens. Am J Clin Oncol 2002; 25 (2): 140-8.

25. Anonymous: Modulation of fluorouracil by leucovorin in patients with advanced colorectal cancer: evidence in terms of response rate. Advanced colorectal cancer meta-analysis project. J Clin Oncol 1992; 10: 896-903.

26. Anonymous: Efficacy of intravenous continuous infusion of 5-fluorouracil comapared with bolus administration in advanced colorectal cancer: Meta-analysis group in cancer. J Clin Oncol 1998; 16: 301-8.

27. Levy-Piedbois C, Durand-Zaleski I, Juhel H, Schmitt C, Bellanger A, Piedbois P. Cost-effectiveness of second-line treatment with irinotecan or infusional 5-fluorouracil in metastatic colorectal cancer. Ann Oncology 2000; 11 (2): 157-61.

28. Calvo E, Cortés J, González-Cao M, Rodríguez J, Aramendia JM, Fernández-Hidalgo $\mathrm{O}$, et al. Combined irinotecan, oxaliplatin and 5flourouracil in patients with advanced colorectal caner. A feasibility pilot study. Oncology 2002; 63: 254-65.

29. Anonymous: oxaliplatin and protracted venous infusion of 5-fluorouracil in patients with advanced or relapsed 5- flourouracil pretreated colorectal cancer. B J Cancer 2001; 85: 1258-64.

30. De Gramont A, Figer A, Seymour M, Homerin M, Hmissi A, Cassidy $\mathrm{J}$, et al. Leucovorin and fluorouracil with or without oxaliplatin as first line treatment in advanced colorectal cancer. J Clin Oncol 2000; 18 : 2938-47.

31. Borner MM, Dietrich D, Stupp R, Morant R, Honegger H, Wernli M, et al. Phase II study of capecitabine and oxaliplatin in first and second line treatment of advanced or metastatic colorectal cancer. J Clin Oncol 2002; 7: 1759-66.

32. Bliberg H, Hendlisz A. Advanced colorectal cancer treatment in Europe: what have we achieved? Review Paper. Anti-Cancer Drugs 2002; 13: 461-71.

33. Meropol NJ, Niedzwiecki D, Hollis D, Schilsky RL, Mayer RJ. Phase II study of oral eniluracil, 5-fluorouracil, and leucovorin in patients 
with advanced colorectal carcinoma. Cancer 2001; 91 (7): 1256-63.

34. Van Custem E, Twelves Ch, Cassidy J, Allman D, Bajetta E, Boyer $\mathrm{M}$, et al. Oral capecitabine compared with intravenous fluorouracil plus leucovorin in patients with metastatic colorectal cancer. Xeloda Colorectal Cancer Study Group. Results of a large phase III study. J Clin Oncol 2001; 19: 4097-106.

35. De Gramont A, Bosset JF, Milan C, Rougier P, Bouche O, Etienne $\mathrm{PL}$, et al. Randomized trial comparing monthly low-dose leucovorin and fluorouracil bolus with bimonthly high-dose leucovorin and fluorouracil bolus plus continuous infusion for advanced colorectal cancer. A French Intergroup study. J Clin Oncol 1997; 15: 808-15.

36. Lokich JJ, Ahlgren JD, Gullo JJ, Philips JA, Fryer JG. Aprospective randomized comparasion of continuous infusion fluorouracil with conventional bolus schedule in metastatic colorectal carcinoma. A Mid-Atlantic Oncology Program Study. J Clin Oncol 1989; 7: 425-32.

37. Anonymus: Efficacy of intravenous continuous infusion of 5-fluorouracil compared with bolus administration in advanced colorectal cancer. Meta-analysis group in cancer. J Clin Oncol 1998; 16: 301-8.

38. Saltz LB, Cox JV, Blanke C, Rosen LS, Fehrenbacher L, Moore MJ, et al. Irinotecan plus fluorouracil and leucovorin for metastatic colorectal cancer. Irinotecan Study Group. N Engl J Med 2000; 343: 90514.

39. Douillard JY, Cunningham D, Roth AD, Navarro M, Karasek P, Jandik P, et al. Irinotecan combined with fluorouracil compared with fluorouracil alone as first-line tretament for metastatic colorectal cancer. A multicenter randomised trial. Lancet 2000; 355: 1041-7.

40. Tsavaris N, Kosmas Ch, Vadiaka M, Koufos Ch. Raltitrexed (Tomudex) administration in patients with relapsed metastatic colorectal cancer after weekly irinotecan/5-fluorouracil/leucovorin chemotherapy. BMC Cancer 2002; 2 (1): 2-15.

41. Grávalos Castro C, Pérez Escutia MA. Tratamiento adyuvante del cáncer colorrectal. Cir Esp 2003; 73 (1): 38-45.

42. Maughan TS, James RD, Kerr DJ, Ledermann JA, McArdle C, Seymour MT, et al. Comparison of survival, palliation, and quality of life with three chemotherapy regimen in metastatic colorectal cancer: a multicentre randomised trial. Lancet 2002; 359: 1555-63.

43. Yonemura Y, Fujimura T, Fushida S, Takegawa S, Kamata T, Katayama K, et al. Hypoerthermo-chemotherapy combined with cytoreductive surgery for the treatment of gastric cancer with peritoneal dissemination. World J Surg 1991; 15 (4): 530-6.

44. Gertsch P. A historical perspective on colorectal liver metastases and peritoneal carcinomatosis: similar results, different treatments. Surg Oncol Clin N Am 2003; 12: 531-41.

45. Sugarbaker PH. Management of peritoneal-surface malignancy: the surgeon's role. Langenbeck's Arch Surg 1999; 384: 576-87.

46. Sugarbaker PH. Peritonectomy procedures. Ann Surg 1995; 221: 2942 .

47. Sugarbaker PH. Peritonectomy procedures. Surg Oncol Clin N Am 2003; 12: 703-27.

48. Yonemura Y. Principles of the treatment of peritoneal dissemination. In: Yonemura Y, eds. Peritoneal dissemination-molecular mechanisms and the latest therapy. Kanazawa: Maeda Shoten Co, Ltd; 1998. Chapter 11, p. 175-90.

49. Sugarbaker PH. It's what the surgeon doesn't see that kills the patient. Nippon Med Sch 2000; 67 (1): 5-8.

50. Dubé P, Lasser Ph, Elias D. Traitement de la carcinose peritoneale dórigine colorectal. J Chir (Paris) 1997; 134 (5-6): 233-6.

51. Elias DM, Pocard M. Treatment and prevention of peritoneal carcinomatosis from colorectal cancer. Surg Oncol Clin N Am 2003; 12: 54359.

52. Gilly FN. Rationale for peritonectomy and perioperative intraperitoneal chemotherapy. Peritoneal Surface Malignancy. Third Biannual Masterclass in Peritoneal Surface malignancy. Basingstoke, Dic 2002.

53. Weissberger AS, Levine B, Storaasli JP. Use of nitrogen mustard in treatment of serous effusions of neoplastic origin. JAMA 1955; 159: 1704-7.

54. Dedrick RL, Myers CE, Bungay PM, DeVita VT Jr. Pharmacokinetic rationale drug administration in the treatment of ovarian cancer. Cancer Tret Rep 1978; 62: 1-9.

55. Katz MH, Barone RM. The rationale of perioperative intraperitoneal chemotherapy in the treatment of peritoneal surface malignancies. Surg Oncol Clin N Am 2003; 12: 673-88.

56. Shen P, Levine EA, Hall J, Case D, Russell G, Fleming R, et al. Fac- tors predicting survival after intraperitoneal hyperthermic chemotherapy with mitomycin $\mathrm{C}$ after cytoreductive surgery for patients with peritoneal carcinomatosis. Arc Surg 2003; 138: 26-33.

57. Sugarbaker PH, Gianola FJ, Speyer JL, Wesley R, Barofsky I, Myers CE. Prospective, randomized trial of intravenous versus intraperitoneal 5- fluorouracil in patients with advanced primary colon or rectal cancer. Surgery 1985; 98: 414-21.

58. Gilly FN, Sayag AC, Carry PY, Brillon G, Roche M, James I, et al. Chimio- hyperthermie intra-peritoneale (CHIP) dans le traitament des carcinoses peritoneales dórigine digestive. Rapport d'une observation et données physiopathologiques. J Chir (París) 1990; 127 (2): 95-8.

59. Fujimoto S, Shrestha RD, Kokubun M, Ohta M, Takahashi M, Kobayashi K, et al. Intraperitoneal hyperthermic perfusion combined with surgery effective for gastric cancer patients with peritoneal seeding. Ann Surg 1988; 208: 36-41.

60. Koga S, Hamazoe R, Maeta M, Shimizu N, Murakami A, Wakatsuki T. Prophylactic therapy for peritoneal recurrence of gastric cancer by continuous hyperthermic peritoneal perfusion either mitomycine $\mathrm{C}$. Cancer 1988; 61: 232-7.

61. Elias D, Dube P, Bonvalot S, Meshaka P, Manai M, Cavalcanti A, et al. Treatment of liver metastases with moderate peritoneal carcinomatosis by hepatectomy and cytoreductive surgery follow-ed by immediate postoperative intraperitoneal chemotherapy: feasibility and preliminary results. Hepatogastroenterol 1999; 46: 360-3.

62. Sticca RP, Dach BW. Rationale for hyperthermia with intraoperative intraperitoneal chemotherapy agents. Surg Oncol Clin N Am 2003; 12: 689-801.

63. Shido A, Ohmura S, Yamamoto K, Konayashi T, Fujimura T, Yonemura Y. Does hyperthermia induce peritoneal damage in continuous hyperthermic peritoneal perfusion? World J Surg 2000; 24 (5): $507-$ 11.

64. Spratt JS, Adcock RA, Sherill W, Travathen S. Hyperthermic peritoneal perfusion system in canines. Cancer Res 1980; 40: 253-5.

65. Spratt JS, Adcock RA, Muskovin M, Sherrill W, McKeown J. Clinical delivery system for intraperitoneal hyperthermic chemotherapy. Cancer Res 1980; 40: 2563-5.

66. Stuart OA, Stephens AD, Welch L, Sugarbaker PH. Safety monitoring of the coliseum technique for heated intraoperative intraperitoneal chemotherapy with mitomycin C. Ann Surg Oncol 2002; 9 (2): 18691.

67. Fujimoto S, Shrestha RD, Kokubun M, Kobayashi K, Kiuchi S, Ohta $\mathrm{M}$, et al. Pharmacokinetic analysis of mitomycin $\mathrm{C}$ for intraperitoneal hyperthermic perfusion in patients with far-advanced or recurrent gastric cancer. Reg Cancer Treat 1989; 2: 198-202. Gan To Kagaku Ryoho. 1989;16 (7): 2411-5. Japanese.

68. Panteix G, Guillaumont M, Cherpin L, Cuichard J, Gilly FN, Carry PY, et al. Study of the pharmacokinetics of mitomycin C in humans during intraperitoneal chemothermia with special mention of the concentration in local tissues. Oncology 1993; 50: 366-70.

69. Jacquet P, Averbach A, Stephens AD, Stuart OA, Chang D, Sugarbaker PH. Heated intraoperative intraperitoneal mitomycin $\mathrm{C}$ and early postoperative intraperitoneal 5- fluorouracil: pharmacokinetic studies. Oncology 1998; 55 (2): 130-8.

70. Elias D, El Otmany A, Bonnay M, Pci A, Ducreux M, Antoun S, et al Human pharmacokinetic study of heated intraperitoneal oxaliplatin in increasingly hypotonic solutions after complete resection of peritoneal carcinomatosis. Oncology 2002; 63: 346-52.

71. Elias DM, Sideris L. Pharmacokinetics of heated intraoperative intraperitoneal oxaliplatin after complete resection of peritoneal carcinomatosis. Surg Oncol Clin N Am 2003; 12: 755-69.

72. Elias DM, Pocard M. Treatment and prevention of peritoneal carcinomatosis from colorectal cancer. Surg Oncol Clin N Am 2003; 12: 54359.

73. Wientjes MG, Badalament RA, Wang RC, Hassan F, Au JL. Penetration of mitomycin C in human bladder. Cancer Res 1993; 53: 3314 31.

74. Glehen O, Gilly FN. Quantitative prognostic indicators of peritoneal surface malignancy: carcinomatosis, sarcomatosis, and peritoneal mesothelioma. Surg Oncol Clin N Am 2003; 12: 649-71.

75. Gómez Portilla A, Sugarbaker PH. Segunda cirugía (second look) después de citorreducción y quimioterapia intraperitoneal en la carcinomatosis por cáncer colorrectal: análisis de factores pronósticos. Cir Esp 1997; 61: 240-5. 
76. Gómez Portilla A, Deraco M, Sugarbker PH. Clinical pathway for peritoneal carcinomatosis from colon and rectal cancer: guidelines for current practice. Tumori 1997; 83 (Supl.): 725-8.

77. Gómez Portilla A, Sugarbaker PH, Chang D. Second-look surgery after cytoreduction and intraperitoneal chemotherapy for peritoneal carcinomatosis from colorectal cancer: analysis of prognosis features. World J Surg 1999; 23: 23-9.

78. Jacquet P, Stephens AD, Averbach AM, Chang D, Ettinghausen SE, Dalton RR, et al. Analysis of morbidity and mortality in 60 patients with peritoneal carcinomatosis treated by cytoreductive surgery and heated intraoperative intraperitoneal chemotherapy. Cancer 1996; 77 : 2622-9.

79. Esquivel J, Vidal-Jove J, Steves MA, Sugarbaker PH. Morbidity and mortality of cytoreductive surgery and intraperitoneal chemotherapy. Surgery 1993; 113: 631-6.

80. Stephens AD, Alderman R, Chang D, Edwards GD, Esquivel J, Sebbag $\mathrm{G}$, et al. Morbidity and mortality analysis of 200 treatments with cytoreductive surgery and hyperthermic heated intraoperative intraperitoneal chemotherapy using the coliseum technique. Ann Surg Oncol 1999; 6: 790-6.

81. Dromain C, Bisdorff A, Elias D, Antoun S, Boige V, Lasser P, et al. Computed tomographic features of peritoneal carcinomatosis treated by intraperitoneal chemohyperthermia. J Comput Assist Tomogr 2003; 27 (3): 327-32.

82. Loggie BW, Fleming RA. Complications of heated intraperitoneal chemotherapy and strategies for prevention. Cancer Treat Res 1996; 82: 221-33.

83. McQuellon RP, Loggie BW, Lehman AB, Russell GM, Fleming RA, Shen $\mathrm{P}$, et al. Long-term survivorship and quality of life after cytoreductive surgery plus intraperitoneal hyperthermic chemotherapy for peritoneal carcinomatosis. Ann Surg Oncol 2003; 10 (2): 155-62.

84. Horsell KW, Merten S, Clingan P, King DW, Morris DL. Peritonectomy and intraperitoneal chemotherapy in appendiceal and colorectal cancer. Aust N Z J Surg 1999; 69 (10): 729-32.

85. Witkamp AJ, de Bree E, Kaag MM, Van Slooten GW, Van Coervorden F, Zoetmulder FAN. Extensive surgical cytoreduction and intraoperative hyperthermic intraperitoneal chemotherapy in patients with pseudomyxoma peritonei. Br J Surg 2001; 88: 458-63.

86. Witkamp AJ, de Bree E, Kaag MM, Boot H, Beijnen JH, van Slooten $\mathrm{GW}$, et al. Extensive cytoreductive surgery followed by intra-operative hyperthermic intraperitoneal chemotherapy with mitomycin-C in patients with peritoneal carcinomatosis from colorectal origin. Eur $\mathbf{J}$ Cancer 2001; 37: 979-84.

87. Yamaguchi A, Tsukoika Y, Fushida S, Kurosaka Y, Kanno M, Yonemura Y, et al. Intraperitoneal hyperthermic treatment for peritoneal dissemination of colorectal cancers. Dis Colon Rectum 1992; 35 (10): 964-8.

88. Schneebaum S, Arnold MW, Staubus A, Young DC, Dumond D, Martin EW Jr. Intraperitoneal hyperthermic perfusion with mitomycin $\mathrm{C}$ for colorectal cancer with peritoneal metastases. Ann Surg Oncol 1996; 3: 44-50.

89. Sugarbaker PH, Chang D. Results of treatment of 385 patients with peritoneal surface spread of appendiceal malignancy. Ann Surg Oncol 1996; 6 (8) : 727-31.

90. Cavaliere F, Perri P, Di Filippo F, Giannarelli D, Botti C, Cosimelli $\mathrm{M}$, et al. Treatment of peritoneal carcinomatosis with intent of cure. $\mathrm{J}$ Surg Oncol 2000; 74: 41-4.

91. Elias D, Dubé P, Blot F, Bonvallot S, Eggenspieler P, Sabourin JC, et al. Peritoneal carcinomatosis treatment with curative intent: the Institute Gustave-Roussy experience. Eur J Surg Oncol 1997; 23: 317-21.

92. Elias D, Gachot B, Bonvallot S, Blot F, Sabourin JC, Ducreux M, et al. Carcinoses peritoneales traitees par exerese complete et chimiotherapie intra-peritoneale postoperatoire immediate (CIPPI). Etude de phase II portant sur 54 malades. Gastroenterol Clin Biol 1997; 21: 181-7.

93. Elias D, Antoun S, Raynard B, Puizillout JM, Sabourin JC, Ducreux M, et al. Traitement des carcinoses peritonelaes par exerese complete et chimiohyperthermie intraperitoneale. Etude de phase I-II permettant de definir la meilleure procedure technique. Chirurgie 1999; 124: 380-9.

94. Elias D, Blot F, El Otmany A, Antoun S, Lasser P, Boige V, et al. Cu- rative treatment of peritoneal carcinomatosis arising from colorectal cancer by complete resection and intraperitoneal chemotherapy. Cancer 2001; 92: 71-6.

95. Loggie BW, Fleming RA, McQuellon RP, Russell GB, Geisinger KR. Cytoreductive surgery with intraperitoneal hyperthermic chemotherapy for disseminated peritoneal cancer of gastrointestinal origin. Am Surgeon 2000; 66: 561-8.

96. Fujimura T, Yonemura Y, Fujita H, Michiwa Y, Kawamura T, Nojima N, et al. Chemohyperthermic peritoneal perfusion for peritoneal dissemination in various intra-abdominal malignancies. Int Surg 1999; 84 (1): 60-6.

97. Beaujard AC, Glehen O, Caillot JL, Francois Y, Bienvenu J, Pantiex $\mathrm{G}$, et al. Intraperitoneal chemohyperthermia with mitomycin $\mathrm{C}$ for digestive tract caner patients with peritoneal carcinomatosis. Cancer 2000; 88 (11): 2512-9.

98. Piso P, Bektas H, Werner U, Schlitt HJ, Kubicka S, Bornscheuer A, et al. Improved prognosis following peritonectomy procedures and hyperthermic intraperitoneal chemotherapy for peritoneal carcinomatosis from appendiceal carcinoma. Eur J Surg Oncol 2001; 27: 286-90.

99. Rey Y, Porcheron J, Talabard JN, Szanfnicki K, Balique JG. Carcinoses peritoneales traitees par chirurgie de reduction tumorale et chimiohyperthermie intraperitoneale. Ann Chir 2000; 125: 631-42.

100. Porcheron J, Talabard JN, Breton C, Szafnicki K, Luxembourger O, Dufraisse $\mathrm{G}$, et al. Intraperitoneal chemohyperthermia for peritoneal carcinomatosis: original modelling, clinical tolerance and results study about 30 patients. Hepatogastroenterology 2000; 47: 1411-8.

101. Vaira M, Scuderi S, Castamagna D, Barone R, Aemo B, Mioli PR, et al. Cytoreductive surgery and intraperitoneal hyperthermic-antiblastic therapy (HAPP) in peritoneal carcinomatosis. Minerva Chir 2002; 57 (5): 579-605.

102. Shen P, Levine EA, Hall J, Case D, Russell G, Fleming RA, et al. Factors predicting survival after intraperitoneal hyperthermic chemotherapy with mitomycin $\mathrm{C}$ after cytoreductive surgery for patients with peritoneal carcinomatosis. Arch Surg 2003; 138: 26-33.

103. Pilati P, Mocellini S, Rossi CR, Foletto M, Campana L, Nitti D, et al. Cytoreductive surgery combined with hyperthermic intraperitoneal intraoperative chemotherapy for peritoneal carcinomatosis arising from colon adenocarcinoma. Ann Surg Oncol 2003; 10 (5): 508-13.

104. Glehen O, Mithieux F, Osinsky D, Beaujard AC, Freyer G, Guertsch $\mathrm{Ph}$, et al. Surgery combined with peritonectomy procedures and intraperitoneal chemohyperthermia in abdominal cancers with peritoneal carcinomatosis: a phase II study. J Clin Oncol 2003; 21 (5): 799-806.

105. Sugarbaker Ph, Jablonski KA. Prognostic features of 51 colorectal and 130 appendicel cancer patients with peritoneal carcinomatosis treated by cytoreductive surgery and intraperitoneal chemotherapy. Ann Surg 1995; 221: 124-32.

106. Sugarbaker PH, Schellinx MET, Chang D, Koslowe P, Von Meyerfeldt M. Peritoneal carcinomatosis from adenocarcinoma of the colon. World J Surg 1996; 20: 585-92.

107. Zoetmulder FAN, Verwaal V. Hyperthermic intraperitoneal chemotherapy (HIPEC) with mitomycin C significantly improves survival in patients with peritoneal carcinomatosis of colorectal origin (abstract) ASCO Prog Proc 2002; 21: 147a.

108. Zoetmulder FAN. Prevention and treatment of carcinomatosis from colon cancer. Peritoneal Surface Malignancy. Third Biannual Masterclass in Peritoneal Surface Malignancy. Basingstoke Dic 2002.

109. Zoetmulder FAN. Hyperthermic intrapoeritoneal chemotherapy in peritoneal carcinomatosis. XXXVIII Congress of the European Society for Surgical Research, Ghent, Belgium May. 2003.

110. Verwaal VJ, Van Ruth S, De Bree E, Van Slooten GW, Van Tinteren $\mathrm{H}$, Boot $\mathrm{H}$, et al. Randomized trial of cytoreduction and hyperthermic intraperitoneal chemotherapy versus systemic chemotherapy and palliative surgery in patients with peritoneal carcinomatosis of colorectal cancer. J Clin Oncol 2003; 21: 3737-43.

111. Elias D, Ouellet JF, Bellon N, Pignon JP, Pocard M, Lasser P. Extrahepatic disease does not contraindicate hepatectomy for colorectal liver metastases. Br J Surg 2003; 90 (5): 567-74. 